\title{
PENGARUH PEMANFAATAN MEDIA FLASH CARD TERHADAP PENGENALAN PRA MEMBACA ANAK USIA 4-6 TAHUN DI TK NURYA BIL ILMA JEMBER
}

\author{
Kustiyowati ${ }^{1)}$ \\ 1) IKIP PGRI Jember \\ wathiesmile@gmail.com
}

\begin{abstract}
ABSTRAK: Proses pembelajaran pra membaca pada saat observasi awal guru belum menggunkan media secara optimal. Guru kurang kreatif dalam menciptakan permainan yang mengedukasi anak. Guru membelajarakan pra membaca dengan cara mengenalkan huruf yang terpisah dengan langsung menujuk dan menyebut bunyinya. Penelitian ini bertujuan untuk mengetahui pengaruh pemanfaatan media flash card terhadap pengenalan pra membaca anak usia 4-6 tahun di TK Nurya Bil Ilma Jember. Metode penelitian yang digunakan adalah bersifat eksperimen semu (quasi experiment) atau dengan desain one shot case study. Teknik analisis data menggunakan rumus Chi Quadrat. Subyek penelitian adlah anak usia 4-6 tahun di TK Nurya Bil Ilma Jember yang berjumlah 25 orang. Metode pengumpulan data dalam penelitian ini menggunakan metode observasi, dan dokumentasi. Hasil penelitian menunjukan bahwa analisis Chi Kuadrat menghasilkan $\mathrm{X}^{2}$ hitung $=5,85$ lebih besar dari X2 tabel $=3,84$ pada taraf signifikansi $5 \%$. Hasilnya menunjukan bahwa ada Pengaruh Pemanfaatan Media Flash Card terhadap Pengenalan Pra Membaca pada anak usia 4-6 tahun di TK Nurya Bil Ilma Jember.
\end{abstract}

Kata kunci : Pemanfaatan Media Flash Card , Pengenalan Pra Membaca

\begin{abstract}
The process of pre-reading learning at the time of initial observation the teacher has not used the media optimally. Teachers are less creative in creating games that educate children. The teacher learns pre-reading by introducing separate letters by directly referring and reciting sounds. This study aims to determine the effect of the use of flash card media on the introduction of pre-reading of children aged 4-6 years at Kindergarten Nurya Bil Ilma Jember. The research method used is quasi-experimental or one shot case study design. Data analysis techniques using the Chi Quadrat formula. The subjects of the research were children aged 4-6 years at Nurya Bil Ilma Jember Kindergarten who numbered 25 people. Data collection methods in this study use the method of observation, and documentation. The results showed that the Chi Square analysis produced $X 2$ count $=5.85$ greater than $X 2$ table $=3.84$ at a significance level of $5 \%$. The results show that there is an influence of the use of flash card media on the introduction of pre-reading in children aged 4-6 years at kindergarten Nurya Bil Ilma Jember.
\end{abstract}

Keywords: Utilization of Flash Card Media, Introduction to Pre Reading

\section{PENDAHULUAN}

Bahasa memiliki peranan yang sangat penting dalam kehidupan, karena bahasa merupakan alat untuk komunikasi baik secara lisan maupun tulisan. Melalui komunikasi kita dapat mengungkapakan fikirian, ide, perasaan dan bertukar informasi dengan orang lain. Kemampuan berkomunikasi dapat diwujudkan dalam empat keterampilan bahasa yaitu kemampuan mendengar, berbicara, membaca dan menulis. Kemampuan berkomunikasi bukan saja diperlukan bagi orang dewasa, tetapi dibutuhkan juga bagi anak-anak. Untuk berkomunikasi anak harus mengenal bahasa, yaitu bahasa Indonesia. Dalam belajar bahasa Indonesia terdapat empat kemampuan. Kemampuan-kemampuan tersebut adalah mendengar, berbicara, membaca dan menulis. Belajar bahasa di TK harus 
mengacu pada Standar Tingkat Pencapaian Perkembangan Anak yang merupakan kriteria minimal. Kualifikasi Standar Tingkat Pencapaian Perkembangan Anak diataranya memuat perkembangan aspek bahasa. Pembelajaran Bahasa di TK diantaranya memahami reseptif bahasa, mengekspresikan bahasa dan keaksaraan ( memahami hubungan bentuk dan bunyi huruf, meniru bentuk huruf, serta memahami kata dalam cerita. Membaca merupakan ketrampilan bahasa tulis yang bersifat reseptif dan itu sebagai pengenalan pra membaca pada anak TK. Kemampuan pra membaca yaitu dengan pengenalan huruf, bunyi, rangkaian huruf, serta pemahaman pada makna.

Penyampaian pengenalan pra membaca di TK segoyanya dikemas dalam pembelajaran yang menyenangkan. Dalam pelaksanaanya agar disesuaikan dengan karakteristik dan tahap perkembangan. Sehingga akan sesuai dengan minat dan tingkat pemahamannya. TK yang merupakan salah satu pendidikan pada anak usia dini mengemban tugas untuk mengembangkan berbagai kemampuan dasar diantaranya bahasa. Pengembangan bahasa pada anak bertujuan untuk mengembangkan kemampuan mendengar, berkomumnikasi, menambah perbendaraan kata dan mengenal simbol-simbol sebagai upaya untuk mengenalkan pra menulis dan membaca. Pengenalan pra membaca di TK harus dilakukan secara interaktif dan menyenangkan. Pembelajaran seyogyanya dilakukan dengan kegiatan permainan dan menggunakan media sebagai alternatif. Dalam proses pembelajaran memerlukan kehadiran seoarang guru yang keratif dan inovatif. Guru pada pendidikan di TK dapat menjadi mitra, fasilitator, model dan motivator bagi anak. Guru hendaknya dalam mengembangkan keterampilan mengajar harus mengagumkan Disamping menemukan poin-poin yang sempuran dari pelajaran yang penting guru dapat mentranfer kegembiraan ke siswa (Davies, 2015: 10)

Peran guru bukan hanya sebatas mendidik tetapi harus dapat memotivasi dan menumbuhkan minat anak dalam pengenalan pra membaca. Pembelajaran harus dapat menciptakan suasana taching-learning yang dapat menumbuhkan rasa dari tidak tahu menjadi tahu (Suherman, 2012: 54). Salah satu cara yang dapat dikenalkan oleh guru dalam pengenalan pra membaca adalah dengan menggunakan media pembelajaran. Pengenalan pra membaca dapat dilakukan dengan memberikan pengalaman membaca dan mengenalkan kata-kata tertulis. Pengalaman ini perlu diberikan agar anak mendapatkan kesempatan untuk berlatih. Pengalaman pra membaca yang diberikan pada anak dapat berupa kegiatan berbicara, mengdengarkan orang lain berbicara dan membaca dengan orang lain. Pengalaman ini diberikan karena pada prinsipnya pembelajaran membaca dan menulis di TK pada kurikulumnya belum diajarkan secara formal. Dengan demikian pembelajaran membaca di TK merupakan tahapan pra membaca. Sesuai dengan tahapan perkembangan, anak TK masih dalam tahap pra operasional. Pada tahapan ini anak memiliki kemampuan berbasa melalui simbol-simbol yang melambangkan.

Membaca merupakan hal yang penting karena sebagai salah satu cara individu untuk mengembangkan pengetahuannya. Membaca merupakan keterampilan berbahasa yang sifatnya reseptif. Dalman (2013: 5) mengatakan bahwa membaca merupakan suatu kegiatan atau proses kognitif yang berupaya untuk menemukan berbagai informasi yang terdapat dalam tulisan. Wasik (2008:326) menerangkan bahasa merupakan sarana 
perkembangan baca tulis. Oleh karena itu bahasa merupakan hal yang harus dikenalkan pada anak. Dua hal dalam pemahaman bahasa (1) Pemahaman Fonemik, pemahaman fonemik diberikan melalui bunyi huruf dan kata-kata yang di dengar, (2) belajar Abjad, manfaat belajar abjad agar anak menggunakan huruf dan keterampilan bunyi huruf untuk persiapan membaca.

Steinberg dalam Susanto (2011:83) mengatakan pra membaca atau membaca dini adalah membaca yang diajarkan secara terprogram pada anak prasekolah. Program ini menitik beratkan pada kata-kata yang utuh, memiliki makna dan diberikan melalui kegiatan permainan sebagai media pembelajaran. Membaca pada anak merupakan kegiatan dalam upaya mendapatkan informasi yang dilakukan dengan bermain agar termotivasi untuk belajar membaca. Latihan para membaca akan lebih efektif jika diberikan pada saat usia dini melalaui kegiatan main. Dhenie (2012: 5) mengutarakan pendapat bahwa membaca permulaan adalah membaca yang diajarkan secara terprogram kepada anak prasekolah. Membaca permulaan merupakan tahap awal dalam membaca yang difokuskan pada mengenal simbol- simbol atau tanda-tanda yang berkaitan dengan huruf-huruf, sehingga menjadi pondasi agar anak dapat melanjutkan ke tahap membaca.

Kemampuan pra membaca merupakan kemampuan yang akan dimiliki anak sebelum membaca yang sesungguhnya. Pra membaca merupakan permulaan belajar membaca dalam mengenal simbol-simbol huruf yang akan dijadikan sebagai landasan dalam membaca awal. Di tahapan ini kemandirian anak mulai muncul tetapi untuk membca kata masih perlu bantuan orang laian misal guru atau orang tua. Oleh karena itu diperlukan pendampingan dan latihan yang terprogram. Jindrich dalam Shofi (2008) mengemukan tingkatan belajar membaca yaitu, (a) memaparkan kata-kata tertulis yang ada disekitar lingkungan anak (b) menumbuhhkan rasa suka pada buku melalui membaca atau melihat orang lain membaca, (c) Mengembangkan koordinasi mata-tangan dan diskriminasi visual, (d) Mengembangkan tracking skill (kemampuan mengikuti kata- kata dari kiri ke kanan, dan dari atas ke bawah), (e) Mempersiapkan kognisi anak agar siap membaca, (f) Mempersiapkan fisik anak agar siap membaca, (g) Mengembangkan kosa kata yang lebih banyak.

Menurut Stainberg (dalam susanto 2011) menyebutkan tahapan perkembangan membaca pada anak yaitu:

a. Timbulnya kesadaran pada tulisan

Anak memulai belajar menggunkan buku dengan cara melihat-lihat, membolak balik dan terkadang bukunya sampai dibawa.

b. Membaca gambar

Anak mulai beranggapan seoelah-olah pembaca. Hal yang dilakukan dengan cara berpura- pura membaca dan tumbuh kesadaran tetntang ciri-ciri buku.

\section{c. Pengenalan bacaan}

Anak Taman Kanak-Kanak mulai dapat menggunakan tiga sistem bahasa, yaiyu fonem (bunyi huruf), semantik ( arti kata), dan sintaksis (aturan kata atau kalimat) secara bersama-sama. Anak yang tertarik pada bahan bacaan mulai mengingat kembali cetakan 
hurufnya dan konteksnya. Anak mulai mengenal tanda-tanda yang ada pada benda-benda di lingkungannya.

d. Membaca lancar

Pada tahap membaca lancar anak mulai membaca buku-buku dengan berbagai jenis dan bahan yang ada kaitannya dengan kehidupan.

Tahapan perkembangan bahasa dikemukakan (Widyastuti, 2017) yaitu (a) tahap fantasi, (b) tahap pembentukan konsep diri, (c) tahap membaca gambar, (d) tahap pengenalan bacaan (e) tahap membaca lancar.

Salah satu cara pengenalan simbol-simbol tulisan dapat dilakukan dengan menggunakan media flashcard. Media flashcard dipilih sebagai salah satu alternatif agar pembelajaran pra membaca pada anak lebih menyenangkan dan bermakna. Media flashcard dapat dimainkan karena berbentuk kartu-kartu gambar dan kata. Media flashcard merupakan salah satu media bentuk permainan edukatif yang berupa kartu gambar dan kata yang sengaja dirancang untuk meningkatkan berbagai aspek perkembangan diataranya bahasa. Media flashcard dalam penggunaanya dapat dilakukan melalui permainan. Anak akan mudah mengingat karena kombinasi antara gambar dan teks dapat memudahkan dalam mengenal konsep-konsep bahasa yang diajarkan. Kemampuan anak dalam pra membaca akan lebih bermakna karena pembelajaran dilakukan dengan interaktif media flashcard. Media ini dapat memotivasi anak untuk lebih berpatisipasi dan aktif dalam pembelajaran. Sehingga anak merasa tidak terbebani meskipun sesungguhnya dia sedang belajar.

Media flash card merupakan salah satu media yang dapat digunakan dalam proses pembelajaran di Taman Kanak-Kanak. Media ini berbentuk kartu bergambar yang dapat diberikan pada anak untuk mengenal huruf dan kata-kata. Gambar dan hurufnya dibuat menarik sehingga membuat anak tertatrik belajar dan bermain dengan cara yang sederhana tetapi bermakna. Riyana (2009:95) mengemukan flash card merupakan media pembelajaran berbentuk kartu gambar dengan ukuran 25X30 cm. Gambar dibuat dari foto atau tangan yang ditempelkan pada lembar flashcard.. Gambar yang ada merupakan rangkaian pesan dan keterangan pada setiap gambar dicantumkan dibagian belakang kartu. Arsyad (2014:115) menyebutkan flashcard merupakan kartu berukuran 8X12 atau yang disesuaikan dan memuat gambar, teks, atau tanda simbol yang mengarahkan siswa pada sesuatu yang berhubungan dengan gambar.

Kasihani menyebutkan flashcards are teaching aids as picture paper which has 25x30. The pictures is made by hand, pictures our photo which is stick on the flashcard. Menurut Izzan (2008:176) menyebutkan Flashcard sebagai alat peraga dari koran dengan ukuran 18X16 inci dengan dilengakapi dengan gambar-gambar menarik, kata, ungkapan ataupun kalimat. Indriana menjelaskan Flashcard sebagai media yang digunakan untuk proses mengajar yang bentuknya berukuran postcard dan kira-kira ukurannya $25 \mathrm{x} 30 \mathrm{~cm}$. Tujuan pembelajaran dengan menggunakan media flashcard melatih otak kanan dalam mengingat gambar dan kata sehingga kemampuan pra membaca anak bisa dilatih sejak dini. Berdasar uraian tersebut dapat disimpulakan bahwa 
flashcard merupakan media pembelajaran dalam bentuk kartu bergambar berukuran 8x12 $\mathrm{cm}$ dan $23 \times 30 \mathrm{~cm}$ atau yang disesuaikan dengan gambar depan berupa simbol, kata, tek dan sisi belakang berupa keterangan yang berhubungan dengan gambar.

Media flash card dapat meningkatkan kemampuan membaca anak dalam hal mengingat bentuk dan gambar ( Yulianti:35). Terdapat beberapa manfaat media flash card yaitu memudahkan anak membaca sejak dini, berkembangnya daya ingat otak kanan dan melatih kosentrasi (Syuropati, 2009 124). Sementara Indriana (2011:138) meyebutkan langkah-langkah dalam menggunakan media flashcard sebagai berikut:

1. Susun kartu dan pegang setinggi dada dihadapkan ke anak

2. Setelah guru menerangkan, kartu diambil satu persatu. Kartu yang sudah diterangkan tersebut diberikan pada anak yang terdekat dengan guru.

3. Anak diminta untuk mengamati kartu lalu dilanjutkan pada anak lainnya sehingga keseluruhan anak mengamati.

4. Jika disajikan dalam permainan, kartu diletakan dalam kotak tampa di susun. Guru akan memerintahkan anak yang berlomba untuk mencari kartu sesuai yang diperintahkan. Kemudian anak kembali ketempat awal untuk menerangkan isi kartu diambil.

Pelaksanaan proses pembelajaran pra membaca pada saat observasi awal guru belum menggunkan media secara optimal. Guru kurang kreatif dalam menciptakan permainan yang mengedukasi anak. Guru membelajarakan pra membaca dengan cara mengenalkan huruf yang terpisah dengan langsung menujuk dan menyebut bunyinya. Melalui cara pembelajaran tersebut terlihat anak kurang memiliki kemampuan dalam merangkai huruf menjadi sebuah kata. Anak sebatas menyebutkan huruf bukan mengenal huruf yang terangkai dalam kata. Anak belum dikenalkan pada perkataan-perkataan utuh dan bermakna dengan memanfaatkan media. Sehingga melalui media flas card diharapkan anak memiliki kemampuan pra membaca kata ataupun gambar dengan cara yang menyenangkan. Oleh karena itu pengenalan pra membaca pada anak harus menjadi pengalaman yang menyenangkan dan mengembirakan.

\section{METODE PENELITIAN}

\section{Jenis Penelitian}

Jenis penelitian ini menggunakan Penelitian eksperimen semu (quasi experiment) dan model eksperimen one shot case study, yaitu sebuah eksperimen yang dilaksanakan tanpa adanya kelompok pembanding dan juga tanpa tes awal (Arikunto,2009:212).Jenis penelitian digunakan untuk mengetahui apa ada pengaruh penerepan media falsh card terhadap penegnalan pra membaca anak usia 4-5 tahun.

\section{Subyek Penelitian}


Subyek dalam penelitian ini adalah seluruh siswa Pada Anak Usia 5-6 tahun di TK Nurya Bil Ilma Jember sebanyak 25 orang.

\section{Teknik pengumpulan data dan Analisa Data}

Pengumpulan data dalam penelitian dilakukan melalui observasi, wawancara dan dokumentasi. Teknik observasi yang digunakan adalah observasi terstruktur. Selanjtnya kegiatan tersebut ditampilakan dalam format skor. Untuk menguji data digunakan teknik analisa dengan rumus Chi Quadrat.

$$
\mathrm{X}^{2}=\sum \frac{(f o-f h)}{f h} \quad \text { (Arikunto 2013) }
$$

Keterangan :

$\mathrm{X}^{2} \quad$ : Chi Kwadrat

Fo : Frekuensi yang diperoleh dari data

Fh : Frekuensi harapan

\section{HASIL DAN PEMBAHASAN}

\section{Data Nilai dari Pemanfaatan Media flash card}

Analisa data yang digunakan dalam penelitian ini adalah analisa statistik Chi Kuadrat. Metode observasi digunakan untuk data hasil penskoran yang meliputi tiga indikator.

1. Nilai 3 digunakan apabila anak Termotivasi melakukan kegiatan

2. Nilai 2 digunakan jika anak melakukan kegiatan Mulai Muncul dengan bantuan

3. Nilai 1 jika belum Belum Termotivasi melakukan kegaiatan

Guna menentukan kategori dari nilai data observasi maka dicari nilai rata-rata, cara penilaiannya dengan menggunakan skor. Dari total skor keseluruhan responden dicari rata-rata untuk menentukan kategori setiap responden. Ketententuan dimaksud adalah,

1. Skor $\geq$ mean maka dikategorikan baik (B)

2. Skor $\leq$ mean maka dikategorikan kurang baik $(\mathrm{K})$

Berikut rumus untuk menentukan rata-rata (mean) adalah sebagai berikut :

$$
\mathbf{M}=\frac{\Sigma X}{\mathrm{~N}} \text { atau } \frac{\text { jumlah semua nilai }}{\text { jumlah sampel }}(\text { Sudjana, } 2005: 67)
$$

Tabel 1. Hasil Observasi Pemanfaatan Media Flash Card

\begin{tabular}{|c|c|c|c|c|c|c|c|}
\hline \multirow{2}{*}{ No resp } & \multicolumn{3}{|c|}{ Pemanfaatan Media Flash Card } & \multirow{2}{*}{ Score } & \multicolumn{2}{|c|}{ Kategori } \\
\cline { 2 - 4 } \cline { 7 - 8 } & $\mathbf{1}$ & $\mathbf{2}$ & $\mathbf{3}$ & $\mathbf{4}$ & & $\mathbf{B}$ & K \\
\hline 1 & 3 & 3 & 3 & 2 & 11 & $\mathrm{~B}$ & \\
\hline 2 & 3 & 3 & 2 & 3 & 11 & $\mathrm{~B}$ & \\
\hline 3 & 2 & 2 & 2 & 2 & 8 & & $\mathrm{~K}$ \\
\hline 4 & 3 & 3 & 2 & 2 & 10 & $\mathrm{~B}$ & \\
\hline
\end{tabular}




\begin{tabular}{|c|l|l|l|l|l|l|l|}
\hline 5 & 3 & 2 & 2 & 2 & 9 & & $\mathrm{~K}$ \\
\hline 6 & 3 & 3 & 3 & 3 & 12 & $\mathrm{~B}$ & \\
\hline 7 & 3 & 2 & 2 & 1 & 8 & & $\mathrm{~K}$ \\
\hline 8 & 2 & 3 & 3 & 3 & 11 & $\mathrm{~B}$ & \\
\hline 9 & 3 & 3 & 2 & 3 & 11 & $\mathrm{~B}$ & \\
\hline 10 & 3 & 3 & 2 & 2 & 10 & $\mathrm{~B}$ & \\
\hline 11 & 2 & 2 & 2 & 2 & 8 & & $\mathrm{~K}$ \\
\hline 12 & 2 & 3 & 3 & 2 & 10 & $\mathrm{~B}$ & \\
\hline 13 & 3 & 2 & 2 & 2 & 9 & & $\mathrm{~K}$ \\
\hline 14 & 3 & 3 & 2 & 2 & 10 & $\mathrm{~B}$ & \\
\hline 15 & 3 & 3 & 3 & 3 & 12 & $\mathrm{~B}$ & \\
\hline 16 & 3 & 3 & 3 & 2 & 11 & $\mathrm{~B}$ & \\
\hline 17 & 3 & 3 & 3 & 2 & 11 & $\mathrm{~B}$ & \\
\hline 18 & 3 & 3 & 3 & 3 & 12 & $\mathrm{~B}$ & \\
\hline 19 & 2 & 2 & 2 & 3 & 9 & & $\mathrm{~K}$ \\
\hline 20 & 3 & 3 & 3 & 3 & 12 & $\mathrm{~B}$ & \\
\hline 21 & 3 & 3 & 3 & 3 & 12 & $\mathrm{~B}$ & \\
\hline 22 & 3 & 2 & 3 & 3 & 11 & $\mathrm{~B}$ & \\
\hline 23 & 3 & 3 & 3 & 3 & 12 & $\mathrm{~B}$ & \\
\hline 24 & 3 & 3 & 2 & 3 & 11 & $\mathrm{~B}$ & \\
\hline 25 & 3 & 3 & 3 & 3 & 12 & $\mathrm{~B}$ & \\
\hline & & & & $\mathbf{2 6 0}$ & $\mathbf{1 9}$ & $\mathbf{6}$ \\
\hline
\end{tabular}

Untuk menentukan mean pada jumlah skor hasil observasi data pemanfaatan media Flash card adalah sebagai berikut :

$$
\begin{aligned}
\mathrm{M} & =\frac{\Sigma \mathrm{X}}{\mathrm{N}} \\
& =\frac{260}{25} \\
& =10,4
\end{aligned}
$$

Dengan demikian dapat diketahui nilai rata-rata 10,4 maka ditetapkan bahwa :

a. Jika nilai responden $\geq 10,4$ maka dikategorikan baik (B)

b. Jika nilai responden $\leq 10,4$ maka dikategorikan kurang baik $(\mathrm{K})$

\section{Data Nilai dari Pengenalan Pra membaca}

Data hasil penskoran pra membaca menggunakan metode obervasi yang terdiri dari 4 item yang berarti :

1. Nilai 4 digunakan apabila anak Termotivasi melakukan kegiatan (T)

2. Nilai 3 digunakan jika anak melakukan kegiatan dengan sedikit bantuan atau Mulai Muncul (MM)

3. Nilai 3 digunakan jika anak melakukan kegiatan dengan banyak bantuan atau Belum Muncul (BM)

4. Nilai 1 jika belum Belum Termotivasi melakukan kegiatan (BT)

Dalam menentukan kategori dari nilai data observasi maka dicari nilai rata-rata sedangkan cara penilaiannya dengan menggunakan skor. Dari total skor keseluruhan 
responden dicari rata- rata untuk menentukan kategori setiap responden. Ketentuanya adalah sebagai berikut :

a. $\quad$ Skor $\geq$ mean maka dikategorikan baik (B)

b. Skor $\leq$ mean maka dikategorikan kurang baik $(\mathrm{K})$

Rumus menentukan rata-rata (mean) adalah sebagai berikut :

$$
\left.\mathbf{M}=\frac{\Sigma X}{\mathrm{~N}} \text { atau } \frac{\text { jumlah semua nilai }}{\text { jumlah sampel }} \text { (Sudjana, } 2005: 67\right)
$$

Tabel 2. Hasil Observasi Pengenalan Pra Membaca

\begin{tabular}{|c|c|c|c|c|c|c|c|}
\hline \multirow[t]{2}{*}{ No resp } & \multicolumn{4}{|c|}{ Pengenalan pra membaca } & \multirow{2}{*}{ Score } & \multicolumn{2}{|c|}{ Kategori } \\
\hline & 1 & 2 & 3 & 4 & & $\mathbf{B}$ & $\mathbf{K}$ \\
\hline 1 & 3 & 3 & 3 & 3 & 12 & B & \\
\hline 2 & 3 & 3 & 3 & 3 & 12 & B & \\
\hline 3 & 3 & 3 & 3 & 3 & 12 & B & \\
\hline 4 & 3 & 3 & 2 & 2 & 10 & & K \\
\hline 5 & 3 & 3 & 3 & 2 & 11 & & $\mathrm{~K}$ \\
\hline 6 & 3 & 3 & 3 & 2 & 12 & B & \\
\hline 7 & 3 & 3 & 2 & 2 & 10 & & $\mathrm{~K}$ \\
\hline 8 & 3 & 3 & 3 & 3 & 12 & B & \\
\hline 9 & 3 & 3 & 3 & 3 & 12 & B & \\
\hline 10 & 3 & 3 & 3 & 2 & 11 & & $\mathrm{~K}$ \\
\hline 11 & 3 & 3 & 3 & 2 & 11 & & $\mathrm{~K}$ \\
\hline 12 & 3 & 3 & 2 & 2 & 10 & & $\mathrm{~K}$ \\
\hline 13 & 3 & 3 & 3 & 2 & 12 & B & \\
\hline 14 & 3 & 3 & 3 & 3 & 12 & B & \\
\hline 15 & 3 & 3 & 3 & 3 & 12 & B & \\
\hline 16 & 3 & 3 & 3 & 3 & 12 & B & \\
\hline 17 & 3 & 3 & 3 & 3 & 12 & B & \\
\hline 18 & 3 & 3 & 3 & 3 & 12 & B & \\
\hline 19 & 3 & 3 & 3 & 3 & 12 & B & \\
\hline 20 & 3 & 3 & 3 & 3 & 12 & B & \\
\hline 21 & 3 & 3 & 3 & 3 & 12 & B & \\
\hline 22 & 3 & 3 & 3 & 3 & 11 & & $\mathrm{~K}$ \\
\hline 23 & 3 & 3 & 3 & 3 & 12 & B & \\
\hline 24 & 3 & 3 & 3 & 2 & 12 & B & \\
\hline 25 & 3 & 3 & 3 & 2 & 12 & $\mathrm{~B}$ & \\
\hline \multicolumn{5}{|c|}{ Jumlah } & 288 & 18 & 7 \\
\hline
\end{tabular}

$$
\mathrm{M}=\frac{288}{25}=11,52
$$


Dengan ketentuan sebagai berikut :

a. Jika nilai responden $\geq 11,52$ maka dikategorikan baik (B)

b. Jika nilai responden $\leq 11,52$ maka dikategorikan kurang baik (K)

Tabel 3. Rekapitulasi Hasil Observasi Pengaruh Pemanfaatan Media Flash Card Terhadap Pengenalan Pra Membaca

\begin{tabular}{|c|c|c|c|c|c|c|c|c|}
\hline \multirow[t]{2}{*}{ No Resp } & \multicolumn{2}{|c|}{$\begin{array}{c}\text { Pemanfaata Media } \\
\text { Flash Card }\end{array}$} & \multicolumn{2}{|c|}{$\begin{array}{c}\text { Pengenalan Pra } \\
\text { membaca }\end{array}$} & \multicolumn{4}{|c|}{$\begin{array}{c}\text { Kategori Hubungan } \\
\text { X-Y } \\
\end{array}$} \\
\hline & Skor & Kategori & Skor & Kategori & BB & BK & KB & KK \\
\hline 1 & 12 & $\mathrm{~B}$ & 12 & $\mathrm{~B}$ & $\sqrt{ }$ & & & \\
\hline 2 & 10 & B & 12 & $\mathrm{~K}$ & & $\sqrt{ }$ & & \\
\hline 3 & 8 & B & 12 & B & $\sqrt{ }$ & & & \\
\hline 4 & 10 & B & 10 & $\mathrm{~K}$ & & $\sqrt{ }$ & & \\
\hline 5 & 9 & $\mathrm{~K}$ & 10 & $\mathrm{~K}$ & & & & $\sqrt{ }$ \\
\hline 6 & 12 & B & 12 & B & $\sqrt{ }$ & & & \\
\hline 7 & 8 & $\mathrm{~K}$ & 10 & $\mathrm{~K}$ & & & & $\sqrt{ }$ \\
\hline 8 & 10 & B & 12 & B & $\sqrt{ }$ & & & \\
\hline 9 & 12 & B & 12 & B & $\sqrt{ }$ & & & \\
\hline 10 & 10 & B & 11 & $\mathrm{~K}$ & & $\sqrt{ }$ & & \\
\hline 11 & 8 & $\mathrm{~K}$ & 11 & $\mathrm{~K}$ & & & & $\sqrt{ }$ \\
\hline 12 & 10 & $\mathrm{~K}$ & 10 & $\mathrm{~K}$ & & & & $\sqrt{ }$ \\
\hline 13 & 9 & $\mathrm{~K}$ & 12 & B & & & $\sqrt{ }$ & \\
\hline 14 & 10 & $\mathrm{~B}$ & 12 & $\mathrm{~B}$ & $\sqrt{ }$ & & & \\
\hline 15 & 12 & B & 12 & $\mathrm{~B}$ & $\sqrt{ }$ & & & \\
\hline 16 & 11 & B & 12 & B & $\sqrt{ }$ & & & \\
\hline 17 & 11 & B & 12 & B & $\sqrt{ }$ & & & \\
\hline 18 & 12 & B & 12 & B & $\sqrt{ }$ & & & \\
\hline 19 & 8 & $\mathrm{~K}$ & 12 & $\mathrm{~B}$ & & & $\sqrt{ }$ & \\
\hline 20 & 12 & $\mathrm{~B}$ & 12 & B & $\sqrt{ }$ & & & \\
\hline 21 & 12 & B & 12 & B & $\sqrt{ }$ & & & \\
\hline 22 & 11 & B & 11 & B & $\sqrt{ }$ & & & \\
\hline 23 & 12 & B & 12 & $\mathrm{~B}$ & $\sqrt{ }$ & & & \\
\hline 24 & 12 & B & 12 & B & $\sqrt{ }$ & & & \\
\hline 25 & 12 & $\mathrm{~B}$ & 12 & B & $\sqrt{ }$ & & & \\
\hline Jumlah & 260 & & 288 & & 16 & 3 & 2 & 4 \\
\hline
\end{tabular}


Tabel 4. Frekuensi Observasi

\begin{tabular}{|c|c|c|c|}
\hline $\begin{array}{c}\text { Pemanfaatan Media } \\
\text { Flash Card }\end{array}$ & \multicolumn{2}{|c|}{ Pengenalan pra membaca } & \multirow{2}{*}{ Jumlah } \\
\hline & Baik & Kurang & \\
\hline Baik & 16 & 3 & 19 \\
\hline Kurang & 2 & 4 & 6 \\
\hline Jumlah & 18 & 7 & 25 \\
\hline
\end{tabular}

\section{Menentukan Frekuensi Harapan}

Untuk mencari besarnya frekuensi haraan (fh) dengan menggunakan rumus.

Fh $=$ Jumlah baris $\mathrm{x}$ jumlah kolom

Fh $(\mathrm{BB})=\frac{19 \times 18}{25}=13,68$

Fh $(B K)=\frac{19 \times 7}{25}=5,32$

Fh $(\mathrm{KB})=6 \frac{\mathrm{x} 18}{25}=4,32$

Fh $(K K)=\frac{6 \times 7}{25}=1,68$

\section{Analisis Data}

\section{Menghitung Nilai Chi Kuadrat}

Dalam menganalisis dan menguji hipotesis yang diajukan pada penelitian ini dengan menggunakan analisis data statistik chi kuadrat sebagai berikut :

$$
X^{2}=\frac{\sum\left(f_{o}-f_{h}\right)^{2}}{f_{h}}
$$

\begin{tabular}{|c|c|c|c|c|c|c|}
\hline $\begin{array}{l}\text { Media Flash } \\
\text { Card }\end{array}$ & $\begin{array}{l}\text { Pengenalan Pra } \\
\text { Membaca }\end{array}$ & Fo & Fh & Fo-fh & $(\text { Fo-fh })^{2}$ & $\frac{(\text { fo-fh })^{2}}{F h}$ \\
\hline B & $\begin{array}{l}\mathrm{B} \\
\mathrm{K}\end{array}$ & $\begin{array}{c}16 \\
3\end{array}$ & $\begin{array}{c}13,68 \\
5,32\end{array}$ & $\begin{array}{c}2,32 \\
-2.32\end{array}$ & $\begin{array}{l}5,38 \\
5,38\end{array}$ & $\begin{array}{l}0.39 \\
1,01\end{array}$ \\
\hline K & $\begin{array}{l}\mathrm{B} \\
\mathrm{K}\end{array}$ & $\begin{array}{l}2 \\
4\end{array}$ & $\begin{array}{l}4,32 \\
1,68\end{array}$ & $\begin{array}{c}-2,32 \\
2.32\end{array}$ & $\begin{array}{l}5,38 \\
5,38\end{array}$ & $\begin{array}{c}1,25 \\
3,2\end{array}$ \\
\hline \multicolumn{2}{|c|}{ Total } & 25 & 25 & & & 5,85 \\
\hline
\end{tabular}

Tabel 5. Perhitungan nilai Chi Kuadrat

Penghitungan tabel diatas diperoleh t angka sebesar 5,85

Menentukan derajar kebebasan $(\mathrm{db})$ 
Derajat kebebasan untuk Chi-Kuadrat adalah $\mathrm{db}=($ baris -1$)($ kolom -1$)$ maka dengan baris sebanyak 2 dan kolom sebanyak 2 maka diperoleh nilai :

$$
\begin{aligned}
& \mathrm{db}=(\text { baris }-1)(\text { kolom }-1) \\
= & (2-1)(2-1) \\
= & 1
\end{aligned}
$$

Konsultasi nilai $\mathrm{X}^{2}$ pada table harga kritik

Tabel 6. Harga Kritik Chi Kuadrat

\begin{tabular}{|c|c|c|c|c|c|c|}
\hline \multirow{2}{*}{ d.b } & \multicolumn{7}{|c|}{ Taraf signifikan } \\
\cline { 2 - 7 } & $\mathbf{5 0} \%$ & $\mathbf{3 0} \%$ & $\mathbf{2 0} \%$ & $\mathbf{1 0} \%$ & $\mathbf{5} \%$ & $\mathbf{1} \%$ \\
\hline 1 & 0,455 & 1,074 & 1,642 & 2,706 & 3,841 & 6,635 \\
\hline 2 & 1,386 & 2,408 & 3,219 & 4,605 & 5,991 & 9,210 \\
\hline 3 & 2,366 & 3,665 & 4,642 & 6,251 & 7,815 & 11,341 \\
\hline 4 & 3,357 & 4,878 & 5,989 & 7,779 & 9,488 & 13,277 \\
\hline 5 & 4,351 & 6,064 & 7,289 & 9,236 & 11,070 & 15,086 \\
\hline
\end{tabular}

(Sugiono, $2015: 456$ )

Dengan d.b $=1$ dan taraf signifikasi $5 \%$ didapat nilai $\mathrm{X}^{2}$ tabel $=3,841$

\section{Pengujian Hipotesis}

Hasil penghitungan diketahui nilai $\mathrm{X}^{2}$ hitung adalah 5,85 sedangkan nilai $\mathrm{X}^{2}$ tabel dengan d. $b=1$ dan taraf signifikasi $5 \%=3,84$. Sehingga nilai $X^{2}$ hitung lebih besar dari $\mathrm{X}^{2}$ tabel, hipotesis nihil ditolak dan hipotesis kerja diterima, engan demikian ada pengaruh Pemanfaatan Media flash card terhadap Pengenalan Pra membaca anak usia 46 tahun di TK Nurya Bil Ilma.

Hasil analisis dan pengujian hipotesis disimpulkan bahwa ada pengaruh pemamfaatan media flash card terhadap pengenalan pra membaca usia 4-6 tahun di TK Nurya Bil Ilma. Hal tersebut sesuai dengan pendapat Hasan (2009: 66) bahwa dengan pemanfaatan media flash card anak dapat membaca dini, menegembangkan daya ingat otak kanan, melatih konsentrasi balita dan memperbanyak perbendaharaan kata. Pemanfaatan media flash card dapat mengembangkan kemampuan membaca anak Taman Kanak-kanak. Ketika anak dipaksakan untuk membaca maka membaca adalah hal yang menakutkan namun sebaliknya apabila cara membelajarkan pra membaca dengan menggunakan media dan permainan maka membaca merupakan kegaiatan yang menyenangkan. Pengaruh pemanfaatan media flash card akan memberikan manfaat untuk peningkatan kemampuan pra membaca pada anak. 


\section{KESIMPULAN}

Berdasarkan hasil uji hipotesis maka dapat disimpulkan bahwa ada pengaruh pemanfaatan media flashcard terhadap pengenalan pra membaca anak usia 4-6 tahun di TK Nurya Bil Ilma. Hal ini dapat dibuktikan dengan hasil analisis dan pengujian hipotesis dengan hasil penghitungan nilai $X^{2}$ hitung adalah 5,85 sementara nilai $X^{2}$ tabel dengan d.b $=1$ dan taraf signifikasi $5 \%=3,84$. Sehingga nilai $X^{2}$ hitung lebih besar dari $\mathrm{X}^{2}$ tabel, hipotesis nihil ditolak dan hipotesis kerja diterima, dengan demikian ada pengaruh Pemanfaatan Media flash card terhadap Pengenalan Pra membaca anak usia 4-6 tahun di TK Nurya Bil Ilma.

\section{DAFTAR RUJUKAN}

Arikunto, S (2013). Prosedur Penelitian Suatu Pendekatan Praktek, Jakarta: Rineke Cipta

Arikunto, S. (2009). Manajemen Penelitian, Jakarta: Rieke Cipta.

Azhar Arsyad, (2015). Media Pembelajaran, Jakarta: Rajawali Press

Berbagai Aspek. Jakarta: Kencana.

Dalman,. 2013. Keterampilan Membaca. Rajawali Pres: Jakarta.

Davies, Caroline Bentley, (2015). Kiat Menjadi Guru yang mengagumkan, Penterjemah Benyamin Molan, Jakarta: Indeks

Depdiknas. 2000. Metode Pengembangan Kemampuan Bahasa. Jakarta: Depdiknas

Dhieni, Nurbiana. 2012. Metode Pengembangan Bahasa. Jakarta: Universitas Terbuka.

Dina Indriana, (2011). Ragam Alat bantu Media Pengajaran, Yogyakarta: Diva Press Hurlock, E B, (1992). Alih bahasa Tjandrasa, M, Perkembangan Anak, Jakarta: Erlangga Izzan, A. (2008). Metodologi pembelajaran Bahasa Inggris. Bandung : Humaniora.

Kasihani K.E Suyanto. (2007)English for Young Learners Melejitkan Potensi Anak Melalui English Class yang Fun, Asyik, dan Menari, Jakarta : Bumi Aksara

Shofi, Ummu. (2008). Sayang Belajar Baca, Yuk. Surakarta. Afra Publishing.

Sugiono, 2015. Metode Penelitian Pendidikan. Bandung : Alfabeta

Suherman Ais, Saondi Ondi, (2010). Etika Profesi Keguruan, Bnadung:Aditama

Susanto, Ahmad. (2011). Perkembangan Anak Usia Dini: Pengantar dalam

Susilana, R. dan Riyana,C. (2009). Media pembelajaran. Bandung : CV Wacana

Prima.

Suyanto, Slamet. 2005. Pembelajaran Untuk Anak TK. Jakarta: Depdiknas

Syuropati, Muhammad. (2009). Inspirasi Anak Anda Dengan Permainan Yang Mencerdaskan. Bantul. In Azna Books. 
Pengaruh Pemanfaatan Media ... (Kustiyowati)

$\overline{\text { Wasik Barbara A \& Carol, (2008). Pendidikan Anak Usia Dini. Terjemahan Plus Nasar. }}$ Jakarta: Rineke Cipta.

Widyastuti, A. (2017). perkembangan kemampuan membaca . jakarta: Elex Media Komputindo.

Yulianti, Reni. Permainan yang meningkatkan kecerdasan anak. Jakarta. Laskar aksara 
Volume 4, Nomor 1, Februari 2020 